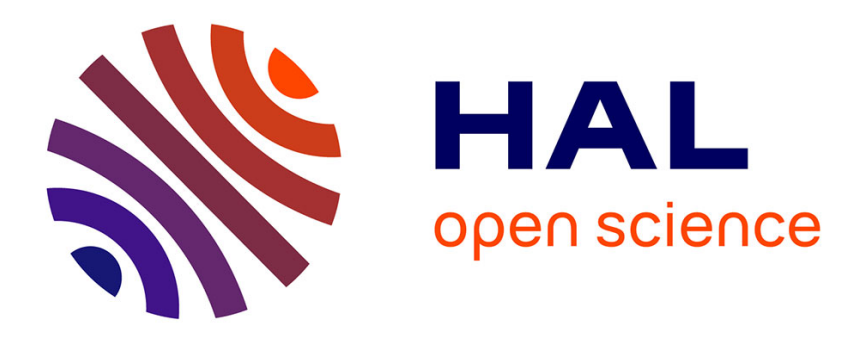

\title{
A Tree-Structured List in a Mathematical Series Text from Mesopotamia
}

\author{
Christine Proust
}

\section{To cite this version:}

Christine Proust. A Tree-Structured List in a Mathematical Series Text from Mesopotamia. Karine Chemla et Jacques Virbel. Texts, Textual Acts and the History of Science, Springer, pp.281-316, 2015, 978-3-319-16444-1. hal-01194325

\section{HAL Id: hal-01194325 \\ https://hal.science/hal-01194325}

Submitted on 5 Sep 2015

HAL is a multi-disciplinary open access archive for the deposit and dissemination of scientific research documents, whether they are published or not. The documents may come from teaching and research institutions in France or abroad, or from public or private research centers.
L'archive ouverte pluridisciplinaire HAL, est destinée au dépôt et à la diffusion de documents scientifiques de niveau recherche, publiés ou non, émanant des établissements d'enseignement et de recherche français ou étrangers, des laboratoires publics ou privés. 


\title{
A tree-structured list in a mathematical series text from Mesopotamia
}

\author{
Christine Proust
}

\author{
Translation Theodora Seal
}

\section{Introduction}

The written culture of the Ancient Near East, whose history covers more than three millennia (from the beginning of the third millennium to the end of the first millennium B.C.), underwent profound transformations over the centuries and showed many faces according to the region of the vast territory in which it developed. Yet despite the diversity of contexts in which they worked, the scholars of Mesopotamia and neighboring regions maintained and consistently cultivated a true 'art of lists', in the fields of mathematics, lexicography astrology, astronomy, medicine, law and accounting. The study of the writing techniques particular to lists represents therefore an important issue for the understanding of the intellectual history of the Ancient Near East.

The cuneiform mathematical texts - most of which date from the Old Babylonian period $\left(20^{\text {th }}\right.$ $17^{\text {th }}$ centuries BC) - are usually given in the format of a succession of problems. Each problem is written in a section delimited by vertical and horizontal lines on the tablet. Thus many mathematical texts can be considered as lists, where each item is defined by a section containing a problem. In the procedure texts ${ }^{1}$, the problems consist of a statement accompanied by a detailed resolution. But, it happens, in particular in the catalogues, that the statement might only be followed by an answer without any explanation. Sometimes, the problems are limited to a statement with neither question nor answer. Some of these lists of statements can reach considerable proportions and cover several successive tablets; they are named series. In the case of the lists of solved problems, the content of each section is generally rich and informative enough to be of interest in itself. For this reason, the procedure texts have rarely been studied as lists. However, in the case of catalogues or series, a section considered individually might show to be poor in content or even incomprehensible. It is then absolutely necessary to identify the structure of the list in order to understand the meaning of the texts. Between the two extremes, namely the list of problems with detailed solutions and the series, all intermediate cases are found. The existence of this continuum stresses the importance of paying attention to the particular meanings conveyed by the list structures, even in the cases where the items are few and self-sufficient.

In this article, I shall consider extreme cases of list structures, and to do this I have chosen very long lists, most items of which are not semantically autonomous. More specifically, I shall study one of the most abstract and concise lists that have come down to us. It belongs to a series, of which one tablet is kept in the Oriental Institute in Chicago (no. A 24194). The study of this case will allow to set forth some of the writing techniques that were particularly developed in the series. Insofar as these techniques are found in other types of mathematical lists, although to a lesser extent, this analysis could lead to a better understanding of a wider

\footnotetext{
${ }^{1}$ The categories of mathematical texts referred to here (procedure texts, catalogue texts, series texts) are those defined by J. Friberg and J. Høyrup; these authors completed the categories previously defined by Neugebauer (Høyrup 2002b, p.9). For more discussion on these classifications, see Proust 2012.
} 
corpus of cuneiform mathematical texts. Further, the strong internal logic of the mathematical texts makes the structure of the lists of problems clearer than that of texts from other genres, for example certain divinatory lists. Thus the study of the structures of the mathematical texts could benefit other areas in Assyriology.

\section{Mathematical series}

As indicated above, a series is a succession of numbered tablets containing a list that runs from one tablet to another. Mathematical series ${ }^{2}$ have very particular characteristics. The tablets end with a colophon ${ }^{3}$ giving the number of sections and the place of the tablet in the series (by its number). The script is logographic: the cuneiform signs represent Sumerian words ${ }^{4}$. The style is extremely concise. The sections only contain the statements, sometimes with a question and an answer, but without any indication of a solution. This set of properties clearly distinguishes the series from other mathematical texts.

Twenty tablets are known to belong to a mathematical series. Today most of them are kept at Yale University, two are in Berlin, two in the Louvre, and two in the Oriental Institute in Chicago ${ }^{5}$. The mathematical series have been studied in depth by Neugebauer in his first publications ${ }^{6}$. But later, they were of little interest to the historians of science, probably because these texts do not provide direct evidence on the methods of solving mathematical problems. The series, however, raise many issues of major interest, for instance questions concerning the language in which the texts were written, their function, their relation to the Old Babylonian scholarly tradition. Neugebauer questioned the link between the writing used in the series and the Sumerian and Akkadian languages. For him, the writing in the Serientexte has nothing to do with a spoken language, and the cuneiform signs could be

\footnotetext{
${ }^{2}$ Neugebauer named them Serientexte in his first publications in German (Neugebauer 1934-6), then series texts in his following publications. Thureau-Dangin used the name textes de séries (Thureau-Dangin 1938, p.214).

3 A colophon is a small additional text usually written at the end of the text on the reverse of the tablet, sometimes on the edges, that gives information on the tablet or its context (number of lines or sections, author, date, name of the text, praise to a good, etc.). In the Old Babylonian period, mathematical texts rarely have colophons; when they do, the colophons are brief (giving one or two pieces of information, not more)

${ }^{4}$ A detailed discussion on the use of Sumerian logograms in mathematical texts is given in Høyrup 2002. Further, it might be useful to recall some pieces of information concerning the written languages in the Ancient Near East. The Sumerian language was written and spoken in southern Mesopotamia during the entire third millennium B.C. Later, Sumerian was supplanted by Semitic languages, in particular Akkadian in the Old Babylonian period. Nevertheless, Sumerian continued to be used in the scribal schools and for scholarly activities during a major part of the second millennium, and was maintained within certain erudite circles until the disappearance of cuneiform writing at the beginning of our era. In their great majority, the mathematical texts are written in Akkadian. Akkadian writing is syllabic, therefore the cuneiform signs represent sounds. However, Sumerian logograms are frequently inserted into this phonetic writing. Although they originally represented words of the Sumerian language, they were probably read in Akkadian. With respect to the mathematical series, the connection between writing and language is more complex (see below). Let us end this note with some points concerning Sumerian. Sumerian words are formed of an invariable root, usually monosyllabic, to which grammatical particles are added: suffixes (which, for example, give the cases for the nouns), prefixes and infixes (for the verbs). For example, in the text examined in this article, the root 'zi' (to subtract) is found alone or in a conjugated form ('ba-zi', I have subtracted).

${ }^{5}$ Yale: YBC 4668, YBC 4669, YBC 4673, YBC 4695, YBC 4696, YBC 4697, YBC 4698, YBC 4708, YBC 4709, YBC 4710, YBC 4711, YBC 4712, YBC 4713, YBC 4714, YBC 4715 (Neugebauer 1935, ch. 7 and Neugebauer 1935-7) ; Berlin : VAT 7528 et VAT 7537 (Neugebauer 1935, ch. 7); Louvre : AO 9071 and AO 9071 (Proust 2009); Chicago : A 24194 and A 24195 (Neugebauer and Sachs 1945, texts T and U).

${ }^{6}$ Neugebauer 1934-6.
} 
considered as mathematical symbols ${ }^{7}$. For the translation of such texts, he therefore chose a word for word style that follows the order of the terms in the cuneiform text; this makes the translation difficult to understand. Moreover, he thought, in a way, that the best translation was that of mathematical formulae:

Many such texts are virtually untranslatable but could best be represented by mathematical formulas. [ Neugebauer and Sachs, p. 3].

As for Thureau-Dangin, he thought that the Sumerian logograms in the series texts as well as those in other mathematical texts ought to be read in Akkadian. He therefore adopted an Akkadian transcription and a more literary translation compared to that of Neugebauer. Another question, also raised by Neugebauer, concerns the function of the text. For him, the mathematical texts are clearly intended for teaching and this is, in his view, particularly clear in tablets A 24194 and A 24195:

This text, like the following one [i.e., A 24194 and A 24195 (C.P.)], can best be compared to an extensive collection of problems from a chapter of a textbook. It is obvious that a collection of this sort was used in teaching mathematical methods. They constitute a large reservoir of problems from which individual problems of any required type (say, speaking from a modern point of view, of a certain category of quadratic equations) could be selected. [Neugebauer and Sachs 1945, p. 116].

This interpretation will be discussed in the conclusion of this article.

Specialists usually consider that the mathematical series texts date back to the end of the Old Babylonian period $\left(17^{\text {th }}\right.$ century BC), and possibly, with respect to the two exemplars in Chicago, to the Kassite period $\left(16^{\text {th }}-12^{\text {th }}\right.$ centuries B.C.). The hypotheses on their origin are varied: Neugebauer and Høyrup are inclined to believe that they come from the northern parts of Mesopotamia; Friberg thinks they come from the southern regions. For my part, I have suggested that the structure of the colophons might speak in favor of a connection between the mathematical series texts and a tradition which developed in Sippar at the end of the dynasty of Hammurabi ${ }^{8}$.

The two tablets kept in Chicago - tablet no. A 24194 and A 24195 - have sides measuring approximately $10 \mathrm{~cm}$ and contain several hundred of statements. Their square shape and extremely dense text distinguishes them from the other mathematical series tablets. The colophon at the end of tablet A 24194 indicates that the tablet contains 240 sections and is the tenth of a series:

$$
4 \text { sixties of sections, } 10^{\text {th }} \text { tablet (4 šu-ši im-šu dub-10-kam-ma) }
$$

Tablet A 24195 does not have a colophon; however, the last column being empty and the penultimate column being only partially inscribed, it seems as if the tablet is unfinished; this could explain the absence of colophon. Because of the numerous similarities between the two tablets in Chicago, including the fact that they have consecutive museum inventory numbers (and therefore must have been purchased at the same time), it is likely that they have the same origin. It is even possible that they belong to the same series.

\footnotetext{
${ }^{7}$ Ibid., p.107.

${ }^{8}$ Reign of Ammi-ṣaduqa (1711-1684); Sippar lies north of the Mesopotamian plain. For a more detailed presentation of the different hypotheses concerning the date and provenance, along with the corresponding bibliography, see Proust 2009.
} 
We shall now concentrate on tablet A 24194. A text extract, which seems representative of the whole, will first be given. Some particular aspects of series will then be discussed: the relation between the statements and the sections; the exact meaning of the Sumerian word 'im-šu' that is given in the colophon; the nature of the statements of the list; the status of the calculations. The article will then be mainly devoted to a study of the text on two scales: that of the entire tablet and that of the sections. An analysis of the relation between these two scales will shed light on the organization and the distribution of information. To conclude I shall tackle again the question of the function of the text. A complete copy of the cuneiform text (appendix 1), a diagram representing the organization and distribution of information within the chosen extract (appendix 2) and a glossary (appendix 3) are given at the end of the article. Given the complexity of the text structure, it will probably be useful to the reader to refer frequently to appendix 2.

Before going further, some information on cuneiform numerical notations and transcription will be given. In cuneiform texts, the numbers used in measure notations (length, area, volume, weight) belong to numerical systems using an additive principle, generally with a sexagesimal structure; these texts can be mathematical, administrative, commercial, legal etc. It is of no help here to go into the details of these systems ${ }^{9}$, because the only metrological notation in our text is that of area (cf infra). In addition to these metrological notations, the mathematical texts use numbers written in a sexagesimal place value notation with 'floating value': the units of a given rank represent 60 units of the preceding one (i.e. to its right); the orders of magnitude are not given $(1,60,1 / 60$ are written in the same manner). The transcription of the number in place value notation chosen here follows Thureau-Dangin's system: the sexagesimal digits are transcribed into a modern Indo-Arab notation; the digits inside a number are separated by dots. Further, in the transcription, the translation and the commentaries, I have kept the floating value notation found in the cuneiform texts. For example, the notation 'uš $\times$ sag $=10$ ' means that the product of the length (uš) and the width (sag) is 10, but it does not indicate how this number 10 is placed in relation to other sexagesimal numbers of the text; in particular, " 10 " does not necessarily mean "10 units" (see $\S 3$ for more details).

Moreover, to facilitate the switching back and forth between the cuneiform text and the modern algebraic representations used to describe the statements, I applied the following principles: in the formulae the terms are written in the same order as the one used in the cuneiform text; the length and the width are denoted by 'uš' and 'sag' respectively (vs. the usual $\mathrm{x}$ and $\mathrm{y}$ ). For example, the text transliterated as 'a-ra 3 uš a-ra 2 sag' meaning ' 3 times the length, two times the width' is represented by the formula: $3 \times$ uš $+2 \times$ sag. It is more difficult to always follow the order of the signs of operation $(+,-, \times)$, because in the ancient text the operators are placed either before or after the arguments, whereas we usually infix them. For example, in the case of addition the ancient order is " A B dah " and the order of the expressions is « $\mathrm{A}+\mathrm{B}$ ». For subtraction the ancient order of terms leads to fairly unusual notations: I chose to represent « $\mathrm{A} B$ zi » by « $-\mathrm{A}+\mathrm{B}$ » (vs. the usual « $\mathrm{B}-\mathrm{A} »)$.

\footnotetext{
${ }^{9}$ The interested reader will find the list of numerical graphemes and the systems to which they belong on the CDLI site (http://cdli.mpiwg-berlin.mpg.de/).
} 


\section{Extract of tablet A 24194}

An extract is given below; it represents only approximately a quarter of the text inscribed on tablet A 24194 (i.e. two columns out of eight). This excerpt is nevertheless sufficient to give a good idea of the main properties of the text. The translation is close to that of Neugebauer: it follows as far as possible the word order of the ancient text, but it is somewhat obscure. For ease of reading, indents and line breaks that highlight the text structure have been added; of course this layout is not found on the original tablet. However, the horizontal lines represented in the table below correspond to the section lines inscribed on the tablet. The first column contains the section numbering (\#), to which I shall refer in the following; the second column contains the line numbering $(l$.). Neither of these is on the original tablet.

Obverse, column 1

\begin{tabular}{|c|c|c|c|}
\hline \# & I. & Transliteration $^{10}$ & $\begin{array}{l}\text { Structured translation } \\
\text { (indents added by the author) }\end{array}$ \\
\hline 1 & $\begin{array}{l}1 . \\
2 . \\
3 . \\
4 . \\
5 . \\
6 .\end{array}$ & $\begin{array}{l}{[\ldots]} \\
\text { a-[...] } \\
\text { igi }[\ldots] \\
20 \text { dah }[\ldots] \\
\text { igi } 7[\ldots] \\
\text { uš-šes dah-ma [32] }\end{array}$ & $\begin{array}{l}{[\ldots]} \\
{[\ldots]} \\
1 / x[\ldots] \\
20 \text { I added }[\ldots] \\
\text { one seventh }[\ldots] \\
\quad \text { to the length } \\
\quad \text { I added: }[32] . \\
\end{array}$ \\
\hline 2 & 7. & a-ra 2 2-e tab dah 34 & 2 times I repeated, I added: 34. \\
\hline 3 & 8. & ba-zi-ma 28 & I subtracted: 28. \\
\hline 4 & 9. & a-ra 2 2-e tab zi 26 & 2 times I repeated, I subtracted: 26. \\
\hline 5 & 10. & a-ra 2 15-e tab-ma uš & 15 times I repeated: the length. \\
\hline 6 & 11. & a-ra 2 20-e tab 10 diri & 20 times I repeated: it exceeded by 10 . \\
\hline 7 & 12. & a-ra 2 10-e tab-ma 10 [ba]-la 2 & 10 times I repeated: it was less by 10 . \\
\hline 8 & 13. & sag-še $e_{3}$ dah 22 & $\begin{array}{l}\text { To the width } \\
\text { I added: } 22 .\end{array}$ \\
\hline 9 & 14. & $\mathrm{a}-\mathrm{ra}_{2} 2-\mathrm{e}<\mathrm{tab}>\mathrm{dah} 24$ & 2 times I repeated, I added: 24. \\
\hline 10 & 15. & zi-ma 18 & I subtracted: 18. \\
\hline 11 & 16. & $\mathrm{a}-\mathrm{ra}_{2} 2-\mathrm{e}<\mathrm{tab}>\mathrm{zi}-\mathrm{ma}[16]$ & 2 times I repeated, I subtracted: 16. \\
\hline 12 & 17. & a-ra 2 10-e tab sag & 10 times I repeated: the width. \\
\hline 13 & 18. & $\mathrm{a}-\mathrm{ra}_{2} 15-\mathrm{e}<\mathrm{tab}>10$ diri & 15 times I repeated: it exceeded by 10 . \\
\hline 14 & 19. & uš sag-še ${ }_{3}$ dah 52 & $\begin{array}{l}\text { To the length and width } \\
\text { I added: } 52 \text {. }\end{array}$ \\
\hline 15 & 20. & $\mathrm{a}-\mathrm{ra}_{2} 2-\mathrm{e}<\mathrm{tab}>\mathrm{dah} 54$ & 2 times I repeated, I added: 54. \\
\hline 16 & 21. & zi 48 & I subtracted: 48. \\
\hline 17 & 22. & $\mathrm{a}-\mathrm{ra}_{2} 2-\mathrm{e}<\mathrm{tab}>\mathrm{zi} 46$ & 2 times I repeated, I subtracted 46. \\
\hline
\end{tabular}

\footnotetext{
10 Transliteration and translation are based on Neugebauer and Sachs 1945, p. 107 ss., as well as on an examination of the tablet I made in November 2010. I warmly thank Walter Farber for the authorization he gave me to work on the mathematical tablets kept at the Oriental Institute of Chicago, and for his kind help. In the translation, I followed exactly the order of the words in the cuneiform text, and chose terms closer to the original meaning (as "repeated" instead of "multiplied"). The importance of the original order will appear later in the chapter. Meaning of transliteration symbols are the following: $[\mathrm{x}$ ] means that the sign $\mathrm{x}$ is destroyed, but that it can be reconstituted thanks to the context; $\langle\mathrm{x}\rangle$ means that the sign $\mathrm{x}$ was omitted by the scribe. In order to simplify the reading for non-specialists, some information has been omitted (for example, half square brackets that designate partially destroyed signs). For a complete transliteration, see Neugebauer and Sachs 1945, p. 107 ss.
} 


\begin{tabular}{|c|c|c|c|}
\hline 18 & 23. & $\mathrm{a}-\left[\mathrm{ra}_{2}\right] 2[5]-\mathrm{e}<\mathrm{tab}>$ uš sag & 25 times I repeated: the length/width. \\
\hline 19 & 24. & a-ra 2 30-e tab 10 diri & 30 times I repeated: it exceeded by 10 . \\
\hline 20 & 25. & a-ra $20-e<t a b>10$ ba-la 2 & 20 times I repeated: it was less by 10. \\
\hline 21 & $\begin{array}{l}26 . \\
27 .\end{array}$ & $\begin{array}{l}\text { a-ra } 23 \text { uš a-ra } 22 \text { sag } \\
\text { dah } 2.12\end{array}$ & $\begin{array}{l}\text { To } 3 \text { times the length, } 2 \text { times the width, } \\
\text { I added: } 2.12 \text {. }\end{array}$ \\
\hline 22 & 28. & $\mathrm{a}^{\mathrm{a}} \mathrm{ra}_{2} 2$ 2-e $<\mathrm{tab}>$ dah 2.14 & 2 times I repeated, I added: 2.14. \\
\hline 23 & 29. & zi-ma 2.8 & I subtracted: 2.8. \\
\hline 24 & 30. & a-ra 2 2-e <tab> zi 2.6 & 2 times I repeated, I subtracted: 2.6. \\
\hline 25 & 31. & [a-ra 2$] 1.5-e<$ tab $>$ uš sag & 1.5 times I repeated: the length/width. \\
\hline 26 & 32. & a-ra $21-e<$ tab $>10$ ba-la 2 & 1 times I repeated: it was less by 10. \\
\hline 27 & 33. & a-ra $_{2} 1.10-\mathrm{e}<\mathrm{tab}>10$ diri & I multiplied by 1.10: it exceeded by 10 . \\
\hline
\end{tabular}

Obverse, column 2

\begin{tabular}{|c|c|c|c|}
\hline 28 & 2. & $\begin{array}{l}\text { [uš u } u_{3} \text { a-na uš ugu sag diri] } \\
\text { [dah-ma 4]2 }\end{array}$ & $\begin{array}{l}\text { [To the length and that by which the length } \\
\text { exceeded the width } \\
\text { I added: } 42 \text { ] }\end{array}$ \\
\hline 29 & 3. & [a-ra 2 2-e tab dah-ma 4]4 & [2 times I repeated, I added: 4]4. \\
\hline 30 & 4. & [zi 38] & [I subtracted: 38.$]$ \\
\hline 31 & 5. & [a-ra 2 2-e tab zi-ma 3]6 & [2 times I repeated, I subtracted: 3]6. \\
\hline 32 & 6. & [a-ra 2 20-e tab-ma uš sa]g & [20 times I repeated: the length]/width. \\
\hline 33 & 7. & [a-ra 2 25-e tab 10 di]ri & [25 times I repeated: ] it exceeded by \\
\hline 34 & 8 & $\begin{array}{l}{\left[\mathrm{a}_{-} \mathrm{ra}_{2}\right.} \\
\text { la }\end{array}$ & $\begin{array}{l}\text { [15 times I repeated: ] it was less by } \\
\text { [10]. }\end{array}$ \\
\hline 35 & $\begin{array}{l}9 . \\
10 . \\
11 .\end{array}$ & $\begin{array}{l}\text { uš [sag u u a-ra } 2 \text { 2] } \\
\text { a-na [uš ugu sag] } \\
\text { [diri dah-ma 1.12] }\end{array}$ & $\begin{array}{l}\text { To the length, [the width and } 2 \text { times] } \\
\text { [that by which the length exceeded the width] } \\
\text { [I added: } 1.12 . \text {. }\end{array}$ \\
\hline 36 & 12. & [a-ra 2 2-e tab dah 1.14] & [2 times I repeated, I added: 1.14.$]$ \\
\hline 37 & 13. & zi-ma [1.8] & I subtracted: [1.8]. \\
\hline 38 & 14. & a-ra 2 2-e $<$ tab $>$ zi 1.6 & 2 times I repeated, I subtracted: 1.6. \\
\hline 39 & 15. & a-ra 2 35-e < tab> uš [sag] & 35 times I repeated: the length/width. \\
\hline 40 & 16. & $\mathrm{a}_{-\mathrm{ra}}[40]$-e $<\mathrm{tab}>10$ diri & 40 times I repeated: it exceeded by 10 . \\
\hline 41 & 17. & a-ra 230 -e tab 10 ba-la 2 & 30 times I repeated: it was less by 10. \\
\hline 42 & $\begin{array}{l}18 . \\
19 . \\
20 . \\
21 . \\
22 . \\
23 .\end{array}$ & 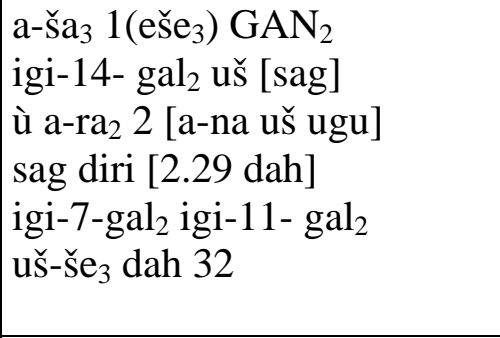 & $\begin{array}{l}\text { The area is } 1\left(\mathrm{eše}_{3}\right) \mathrm{GAN}_{2} \text {. } \\
\text { To one-fourteenth of the length, the width } \\
\text { and } 2 \text { times [that by which the length exceeded] } \\
\text { the width, [2.29 I added], } \\
\text { one-seventh of one-eleventh } \\
\text { to the length } \\
\quad \text { I added: } 32 \text {. }\end{array}$ \\
\hline 43 & 24. & a-ra 2 2-e $<$ tab $>d$ & 2 times I repeated, I added: 34. \\
\hline 44 & 25. & zi 28 & I subtracted: 28. \\
\hline 45 & 26. & a-ra 2 2-[e tab zi 26] & 2 times I repeated, [I subtracted: 26$].$ \\
\hline 46 & 27. & a-ra 2 [15-e tab uš] & [15] times [I repeated: the length]. \\
\hline 47 & 28. & a-ra 2 20-e $<$ tab $>10$ diri & 20 times I repeated: it exceeded by 10 . \\
\hline 48 & 29. & a-ra 2 10-e $<$ tab $>1$ & 10 times I repeated: it was less by 10. \\
\hline 49 & 30. & sag-še $e_{3}$ dah 22 & $\begin{array}{l}\text { To the width } \\
\text { I added: } 22 .\end{array}$ \\
\hline 50 & 31. & a-ra 2 2-e <tab $>$ dah 24 & 2 times I rep \\
\hline
\end{tabular}




\begin{tabular}{|c|c|c|c|}
\hline 51 & 32. & zi 18 & I subtracted: 18. \\
\hline 52 & 33. & a-ra 2 2-e <tab $>$ zi 16 & 2 times I repeated, I subtracted: 16. \\
\hline 53 & 34. & a-ra 2 10-e tab sag & 10 times I repeated: the width. \\
\hline 54 & 35. & $\begin{array}{l}\text { a-ša }{ }_{3} 1\left(\mathrm{eše}_{3}\right) \mathrm{GAN}_{2} \\
\text { (end of statement in the } \\
\text { following column) }\end{array}$ & The area is $1\left(\mathrm{eše}_{3}\right) \mathrm{GAN}_{2}$ \\
\hline
\end{tabular}

The list of statements has apparently a linear structure, since the statements are written one after the other in parallel with no visible hierarchy. However, a closer look reveals a more complex structure. On the one hand, the text is divided into sections of different sizes: long sections (with respect to extract: \#1, unfortunately partly destroyed, and \#42), medium-sized sections (\#8, 14, 21, 28, 35, 49) and short sections (all others). On the other hand the same statements recur - not considering the specific numerical values - cyclically. This applies to the statements of the short sections as well as to those of the medium-sized and long sections. In fact the list is built on cycles of various lengths that are inserted in each other; this will be seen below.

Let us now examine the excerpt formed by sections 42-53, which is relatively well preserved. Section 42 provides some information:

"The area is $1\left(\mathrm{eše}_{3}\right) \mathrm{GAN}_{2}$ " 11 .

The same information is found at the beginning of each long section of the tablet. This area datum gives the product of the length (uš) and the width (sag). According to the metrological tables that were used during the Old Babylonian period, an area of 1(eše $\left.{ }_{3}\right) \mathrm{GAN}_{2}$ corresponds to the number 10. Thus the following “equation” is obtained:

$$
\text { uš } \times \text { sag }=10
$$

(let us recall that this equality is defined up to a power of 60$)^{12}$.

The following three lines define a fairly complicated linear combination of the length (uš) and the width (sag) of a rectangle that will be referred to below as 'main expression, ${ }^{13}$, denoted P:

$$
\mathrm{P}=\left\{\frac{1}{14} \times[\text { uš }+ \text { sag }+2 \times(\text { uš }- \text { sag })]+2.29\right\} \times \frac{1}{7} \times \frac{1}{11} .
$$

Then comes a very simple second expression, "uš”, which I shall designate as 'secondary expression', denoted S. Here:

\footnotetext{
${ }^{11}$ An area of 1 (eše ${ }_{3}$ ) $\mathrm{GAN}_{2}$ (or $6 \mathrm{GAN}_{2}$ ) approximately represents $21600 \mathrm{~m}^{2}$. Indeed, $1 \mathrm{GAN}_{2}$ is equal to 100 sar; a sar is the area of a square of side 1 ninda; a ninda is a unit of length approximately equal to $6 \mathrm{~m}$.

12 This relation can be verified by a very simple calculation: as will be seen below, the length uš corresponds to 30 , the width sag to 20 , therefore the area corresponds to: $30 \times 20=600=60 \times 10$, which is written 10 in the cuneiform 'floating value' system. For more details on the relations between measures and place value notations, see Proust 2008.

${ }^{13}$ This term is inspired from Neugebauer's work; Neugebauer designated the content of the long sections by "main problems" and the content of the others by "variants". Nevertheless, I noted the name of these expressions as "P" (principal) and "S" (secondaire) in order to be coherent with the notations I used in my French publications, as (Proust 2009).
} 


$$
\mathrm{S}=\mathrm{uŠ} \text {. }
$$

Finally, the content of the section ends with a verb, to add (dah), and a result, 32, indicating a relation between $\mathrm{P}$ and $\mathrm{S}$. In modern terms, this relation could be translated by the following formula:

or, if $\mathrm{P}$ and $\mathrm{S}$ are written explicitly:

$$
\mathrm{P}+\mathrm{S}=32
$$

$$
\left\{\frac{1}{14} \times[\text { uš }+ \text { sag }+2 \times(\text { uš }- \text { sag })]+2.29\right\} \times \frac{1}{7} \times \frac{1}{11}+\text { uš }=32 .
$$

Therefore, the statement of section 42 is formed of four segments: the area, the definition of

\begin{tabular}{|c|c|c|}
\hline $\mathrm{a}-\mathrm{s̆a}_{3} 1\left(\mathrm{eše}_{3}\right) \mathrm{GAN}_{2}$ & The area is $1\left(\mathrm{eše}_{3}\right) \mathrm{GAN}_{2}$. & Area \\
\hline $\begin{array}{l}\text { igi-14- gal } 2 \text { uš [sag] } \\
\text { ù a-ra } 2 \text { [a-na uš ugu] } \\
\text { sag diri [2.29 dah] } \\
\text { igi-7-gal }{\text { igi-11- } \text { gal }_{2}}^{2}\end{array}$ & $\begin{array}{l}\text { To one-fourteenth of the length, the width } \\
\text { and two times [that by which the length } \\
\text { exceeded] } \\
\text { the width, [ } 2.29 \text { I added], } \\
\text { one-seventh of one-eleventh }\end{array}$ & Main expression P \\
\hline \multirow[t]{2}{*}{ uš-še $e_{3}$ dah 32} & to the length & $\begin{array}{l}\text { Secondary } \\
\text { expression } S(S=\text { uš })\end{array}$ \\
\hline & I added: 32 . & $\begin{array}{l}\text { Relation between } \mathrm{P} \\
\text { and } \mathrm{S}(\mathrm{P}+\mathrm{S}=32)\end{array}$ \\
\hline
\end{tabular}
the main expression $\mathrm{P}$, the definition of the secondary expression $\mathrm{S}$, and a relation between $\mathrm{P}$ and $\mathrm{S}$. The table below summarizes this segmentation.

Section 43 is short: "2 times I repeated, I added: 34”. What is repeated 2 times (i.e. multiplied by 2)? To what is the result added? As the text is extremely regular and repetitive, it is easy to identify these expressions. The first is the complex linear combination of uš and sag (or main expression P) defined in section 42. The second is uš (or secondary expression S), also defined in section 42 . The statement 43 can therefore be represented by the following formula:

$$
\mathrm{P} \times 2+\mathrm{S}=34
$$

where $\mathrm{P}$ and $\mathrm{S}$ are defined above, in section 42, and are implicitly used in section 43 . This brief statement is thus a reduced formulation of a full statement, which could be expressed in modern language in the following way:

$$
\left\{\frac{1}{14} \times[\text { uš }+ \text { sag }+2 \times(\text { uš }- \text { sag })]+2.29\right\} \times \frac{1}{7} \times \frac{1}{11} \times 2+\text { uš }=34
$$

The next section (\#44) gives another relation between the same expressions $\mathrm{P}$ and $\mathrm{S}$, here too implicit: "I subtracted: 28”:

$$
-\mathrm{P}+\mathrm{S}=28
$$

The following sections (\#45-48) in turn give other relations between these same expressions.

Section 49 is a middle-sized section that introduces a new value for S: 'To the width I added: 22'. $\mathrm{P}$ is no longer added to uš, but to sag:

$$
\mathrm{P}+\mathrm{sag}=22
$$

The following sections give in turn relations between $\mathrm{P}$ and this new value of $\mathrm{S}$. Let us note that this new cycle of relations almost identically reproduces the one of sections 42-48. 
Let us now consider all the sections of the extract. Their content can be represented by the following formulae (when the expressions $\mathrm{P}$ and $\mathrm{S}$ are explicitly given in the cuneiform text, they are given in underlined bold type in the formulae below; see also appendix 2):

\begin{tabular}{|c|c|c|c|c|}
\hline Section & Area & $\mathbf{P}$ & $\mathbf{S}$ & Relation \\
\hline$\# 1$ & uš $\times$ sag $=10$ & ? & uš & $\underline{\mathbf{P}}+\underline{\mathbf{S}}=[32]$ \\
\hline$\# 2$ & " & $"$ & " & $\mathrm{P} \times 2+\mathrm{S}=34$ \\
\hline$\# 3$ & $"$ & $"$ & $"$ & $-P+S=28$ \\
\hline$\# 4$ & " & $"$ & $"$ & $\begin{array}{l}-\mathrm{P} \times 2+\mathrm{S}= \\
26\end{array}$ \\
\hline$\# 5$ & $"$ & $"$ & $"$ & $\mathrm{P} \times 15=\underline{\mathrm{S}}$ \\
\hline \#6 & " & $"$ & $"$ & $\begin{array}{l}\mathrm{P} \times 20=\mathrm{S}+ \\
10\end{array}$ \\
\hline$\# 7$ & $"$ & $"$ & " & $\begin{array}{l}\mathrm{P} \times 10=\mathrm{S}- \\
10\end{array}$ \\
\hline \#8 & " & " & sag & $\mathrm{P}+\underline{\mathbf{S}}=22$ \\
\hline$\# 9$ & " & $"$ & " & $\mathrm{P} \times 2+\mathrm{S}=24$ \\
\hline$\# 10$ & $"$ & " & " & $-P+S=18$ \\
\hline$\# 11$ & $"$ & $"$ & " & $\begin{array}{l}-\mathrm{P} \times 2+\mathrm{S}= \\
16\end{array}$ \\
\hline$\# 12$ & " & $"$ & " & $\mathrm{P} \times 10=\underline{\mathrm{S}}$ \\
\hline$\# 13$ & $"$ & " & " & $\begin{array}{l}\mathrm{P} \times 15=\mathrm{S}+ \\
10\end{array}$ \\
\hline$\# 14$ & $"$ & $"$ & uš + sag & $\mathrm{P}+\underline{\mathrm{S}}=52$ \\
\hline$\# 15$ & $"$ & $"$ & " & $\mathrm{P} \times 2+\mathrm{S}=54$ \\
\hline$\# 16$ & $"$ & $"$ & $"$ & $-P+S=48$ \\
\hline$\# 17$ & $"$ & $"$ & $"$ & $\begin{array}{l}-\mathrm{P} \times 2+\mathrm{S}= \\
46\end{array}$ \\
\hline$\# 18$ & " & $"$ & $"$ & $\mathrm{P} \times 25=\underline{\mathrm{S}}$ \\
\hline$\# 19$ & $"$ & $"$ & $"$ & $\begin{array}{l}\mathrm{P} \times 30=\mathrm{S}+ \\
10\end{array}$ \\
\hline$\# 20$ & $"$ & " & " & $\begin{array}{l}\mathrm{P} \times 20=\mathrm{S}- \\
10\end{array}$ \\
\hline$\# 21$ & $"$ & $"$ & $\begin{array}{l}3 \times \text { uš }+ \\
2 \times \text { sag }\end{array}$ & $\mathrm{P}+\underline{\mathbf{S}}=2.12$ \\
\hline$\# 22$ & " & " & " & $\begin{array}{l}\mathrm{P} \times 2+\mathrm{S}= \\
2.14\end{array}$ \\
\hline$\# 23$ & " & $"$ & $"$ & $-P+S=2.8$ \\
\hline$\# 24$ & $"$ & $"$ & " & $\begin{array}{l}-\mathrm{P} \times 2+\mathrm{S}= \\
2.6\end{array}$ \\
\hline$\# 25$ & " & $"$ & " & $\begin{array}{l}\mathrm{P} \times 1.5 \\
\text { uš/sag }\end{array}$ \\
\hline$\# 26$ & $"$ & $"$ & $"$ & $\mathrm{P} \times 1=\mathrm{S}-10$ \\
\hline$\# 27$ & " & " & $"$ & $\begin{array}{l}\mathrm{P} \times 1.10=\mathrm{S}+ \\
10\end{array}$ \\
\hline$\# 28$ & " & $"$ & $\begin{array}{l}\text { uš + (uš - } \\
\text { sag) }\end{array}$ & $\mathrm{P}+\underline{\mathbf{S}}=42$ \\
\hline
\end{tabular}




\begin{tabular}{|c|c|c|c|c|}
\hline$\# 29$ & " & " & " & $\mathrm{P} \times 2+\mathrm{S}=44$ \\
\hline \#30 & $"$ & $"$ & $"$ & $-P+S=38$ \\
\hline \#31 & " & " & $"$ & $\begin{array}{l}-\mathrm{P} \times 2+\mathrm{S}= \\
36\end{array}$ \\
\hline \#32 & " & $"$ & $"$ & $\mathrm{P} \times 20=\mathrm{S}$ \\
\hline \#33 & " & " & " & $\begin{array}{l}\mathrm{P} \times 25=\mathrm{S}+ \\
10\end{array}$ \\
\hline \#34 & " & " & $"$ & $\begin{array}{l}\mathrm{P} \times 15=\mathrm{S}- \\
10\end{array}$ \\
\hline \#35 & " & " & $\begin{array}{c}\text { uš + sag + } \\
2 \times(\text { uš }- \\
\text { sag) }\end{array}$ & $\mathrm{P}+\underline{\mathbf{S}}=1.12$ \\
\hline \#36 & " & " & " & $\begin{array}{l}\mathrm{P} \times 2+\mathrm{S}= \\
1.14\end{array}$ \\
\hline \#37 & $"$ & " & " & $-\mathrm{P}+\mathrm{S}=1.8$ \\
\hline \#38 & " & " & " & $\begin{array}{l}-2 \times P+S= \\
1.6\end{array}$ \\
\hline \#39 & $"$ & $"$ & $"$ & $\mathrm{P} \times 35=\underline{\mathbf{S}}$ \\
\hline$\# 40$ & " & " & " & $\begin{array}{l}\mathrm{P} \times 40=\mathrm{S}+ \\
10\end{array}$ \\
\hline$\# 41$ & " & " & " & $\begin{array}{l}\mathrm{P} \times 30=\mathrm{S}- \\
10\end{array}$ \\
\hline$\# 42$ & " & $\left\{\frac{1}{14} \times[\right.$ uš + sag $+2 \times($ uš - sag $\left.)]+2.29\right\} \times \frac{1}{7} \times \frac{1}{11}$ & uš & $\underline{\mathbf{P}}+\underline{\mathbf{S}}=32$ \\
\hline$\# 43$ & " & " & $"$ & $\mathrm{P} \times 2+\mathrm{S}=34$ \\
\hline$\# 44$ & $"$ & $"$ & $"$ & $-P+S=28$ \\
\hline$\# 45$ & " & " & " & $\begin{array}{l}-\mathrm{P} \times 2+\mathrm{S}= \\
26\end{array}$ \\
\hline$\# 46$ & $"$ & " & " & $\mathrm{P} \times 15=\underline{\mathrm{S}}$ \\
\hline$\# 47$ & " & " & " & $\begin{array}{l}\mathrm{P} \times 20=\mathrm{S}+ \\
10\end{array}$ \\
\hline$\# 48$ & " & " & " & $\begin{array}{l}\mathrm{P} \times 10=\mathrm{S}- \\
10\end{array}$ \\
\hline$\# 49$ & $"$ & $"$ & sag & $\mathrm{P}+\underline{\mathbf{S}}=22$ \\
\hline$\# 50$ & $"$ & $"$ & $"$ & $\mathrm{P} \times 2+\mathrm{S}=24$ \\
\hline$\# 51$ & $"$ & " & " & $-P+S=18$ \\
\hline$\# 52$ & $"$ & $"$ & " & $\begin{array}{l}-\mathrm{P} \times 2+\mathrm{S}= \\
16\end{array}$ \\
\hline$\# 53$ & $"$ & $"$ & " & $\mathrm{P} \times 10=\underline{\mathrm{S}}$ \\
\hline
\end{tabular}

Section 54 contains the beginning of a statement (continued in column 3) which gives the area and defines another variant of P; the cycles described above for sections 1-41 and 42-53 then recurs in column 3 and following.

The above list of formulae shows several important properties of the text: the regularity of the cycles of statements; the structure of the information (definition of the product uš $\times$ sag, then $\mathrm{P}, \mathrm{S}$, and the relation between $\mathrm{P}$ and $\mathrm{S}$ ); the system of elision of information. Concerning this last point, we note that $\mathrm{P}$ and $\mathrm{S}$ are only given explicitly in a section if these expressions take a new value. In the following sections, they are implicit. However, some exceptions are found 
$(\# 5,12,18)$, where $\mathrm{S}$ is given explicitly, probably for grammatical reasons ${ }^{14}$. In sections 25 and 39, expression $\mathrm{S}$ is named without being fully developed (see below §4 'level 2', some remarks on the names given to the expressions).

\section{Sections, statements and calculations}

After this first partial examination of the text, it is possible to clarify some aspects that were briefly introduced at the beginning of this article.

The first aspect is the relation between the sections and their content. In principle, each section of a series contains a statement and the number of sections $(\mathrm{N})$, which is equal to the number of statements, is given in the colophon according to the expression ' $\mathrm{N}$ im-šu'. However, there are cases where the one-to-one mapping between sections and statements is disrupted. For instance, it may happen that some sections contain two statements, or that some statements begin in a section and end in another, notably in the case of a change of column ${ }^{15}$. When the number of sections and the number of statements on a tablet differ, it is usually the number of statements that is recorded in the colophon. Yet, literally, the term 'im-šu' refers to a physical reality, namely a box bounded by vertical and horizontal lines. Thus, the term 'imšu' is ambivalent: it sometimes designates the container (the box) and sometimes the content (the statement), and it probably most often refers to both ${ }^{16}$. On this subject, let us remark that the only cuneiform tablets in which the expression 'im-šu' is found in a colophon are the mathematical tablets. In the latter, the section is clearly associated with the text unit represented by the problem (possibly reduced to its statement). In other corpuses, for instance certain divinatory texts, the colophons give the number of 'lines' (mu); but, just as it is the case for the mathematical series, the term 'mu' designates both the container (the line) and the content (the sentence) ${ }^{17}$. This comparison highlights the link between the physical unit (section or line), and the textual unit (problem or sentence) ${ }^{18}$. It is difficult to find a translation of the term 'im- šu' that covers these various meanings. Following Neugebauer and ThureauDangin, the literal translation as 'section' has been retained here and in some instances the word 'section' has been used to refer to both the boxes and their content.

However in the tablet that is considered here, the number expressed in the colophon is not quite clear, because it indicates 4 times 60 of 'im-šu' that neither corresponds to the number of sections, nor to the number of statements. This discrepancy cannot be explained.

\footnotetext{
${ }^{14}$ In section 5, for example, if uš had been omitted, the sentence would end with '-ma'; this seems impossible within the syntax of the text. This is quite comprehensible, since it is difficult to imagine a sentence in French that would end with ' $:$ '. The problem is the same in sections 12, 18 and 39. Let us note that in other series texts the difficulty is circumvented by using the verb ' $\mathrm{sa}_{2}$ ', which means 'is equal' (see Proust 2009).

15 The first case is attested to in AO 9071 (Ibid.), the second case in YBC 4712 (Neugebauer 1935, p. 433, n. 12a) and in the present text (as indicated above, section 52 begins at the end of column 2 of the obverse and ends at the beginning of column 3).

16 This double meaning can be compared to that of a word such as 'book': it can denote an object such as 'a library of 300 books', or a text such as '300 copies of the book were printed'.

${ }^{17}$ On this subject, see the typology of the Old Babylonian divination texts developed by J.J. Glassner, in particular that of the series from Sippar, which date from the end of Hammurabi's dynasty $\left(17^{\text {th }}\right.$ century B.C.) (Glassner 2009). Let us note that a 'line' is sometimes more a theoretical entity than a practical one: when a sentence is long, it can be written on two lines

${ }^{18}$ This comparison is also of historical interest. Indeed, careful observation of the colophons suggests that the tradition of the mathematical series is not so different than that of the divination texts studied by J.-J. Glassner, see note above (for more details, see Proust 2009).
} 
The second aspect that must be clarified is the nature of the content of the sections. All the specialists who have studied this type of text acknowledge that the contents of the sections are problem statements, however in my opinion this deserves a justification. Indeed, nowhere in tablet A 24194 is there the slightest allusion to a request to solve a problem: neither questions nor answers are given with the statements. Further, the grammatical structure is so poor that it is doubtful that the text is written in the first person, as it is usually the case for problem statements in cuneiform texts. But, if we turn to other mathematical series texts, one can see that many of them consist of similar statements, more obviously written in the first person singular, and followed by a question ('What are the length and the width ?') and sometimes by an answer, which is always the same ('The length is 30 and the width is 20'). In these cases the statements are clearly problems that are to be solved. Is it the same for our text? In fact, tablets A 24194 and A 24195 are quite different from those belonging to the other known mathematical series and it is doubtful that the function or even the nature of the texts is the same. It is possible that the two Chicago tablets might be more recent and that their authors developed techniques to elaborate statements on the basis of an existing tradition, but for different purposes. In order to provide a more reliable answer, let us consider the question of the nature of the statements from a mathematical point of view. All the information provided explicitly or implicitly in each section consists in two relations between the length and the width of a rectangle. The first gives the area of the rectangle, thus the product of the length and the width; the second gives a linear relation between the two dimensions. Considering the length and the width as unknowns, the necessary and sufficient information is available for the calculation of these unknowns. It is difficult to ascribe such a strong mathematical property to chance. For this reason, the statements of tablet A 24194 are indeed problem statements, whose unknowns are the length and the width, each consisting of two 'equations, ${ }^{, 19}$. In modern mathematical language, one would say that the content of each section describes (explicitly or implicitly) a quadratic system of two equations with two unknowns.

Do these statements refer to calculations? The text does not explicitly mention calculations since the problems are given, but are not solved. However, as the solution is always the same (i.e. us $=30$ and sag $=20$ ), the elaboration of the statements requires calculations ensuring that the chosen data lead to this immutable solution decided in advance. The calculations are not intended to solve the problems, but to produce problems.

What exactly are these calculations? The answer is probably not the same for the reader and for the writer of the text. As has been seen, the reader is not asked explicitly to solve the problems, maybe not even implicitly. But he is encouraged, if only to control his reading of the text, to verify that the statement leads to the correct solution. The calculations thus consist in replacing uš by 30 and sag by 20 and then performing the operations given in the statements in their order of occurrence. It appears as if, when the statements were read, they functioned as instructions. J. Virbel, in his contribution to this book, has given other examples of lists that vary in nature depending on the person using it and his intentions ${ }^{20}$. The process

\footnotetext{
${ }^{19}$ The word equation is understood here in a very broad sense: a numerical relation between two unknown magnitudes.

${ }^{20}$ See the example of the list of food lacking in a house which, in the hands of the person shopping, can be used to carry out the act of giving instructions (p. xxx). Other examples have been suggested by J. Virbel: ' $a$ very large number of texts have both the status of an assertion and that of an order (and often also of commitment): the agenda of a meeting, the menu of a restaurant' (REHSEIS seminar, September 2008; see Chapter 4, section IV).
} 
seems to have been different for the writer of our text, since it consisted in adjusting the data in order to produce problems with solution 30 and 20. It is possible to identify certain values in the statements that were more specifically subject to these adjustments; table 1 below identifies them for the first cycle of statements, but it could be reproduced almost identically for the other cycles:

\begin{tabular}{|c|c|}
\hline$\#$ & The adjustment concerns \\
\hline 1 & the result: 32 \\
\hline 2 & the result: 34 \\
\hline 3 & the result: 28 \\
\hline 4 & the result: 26 \\
\hline 5 & the factor of $P: 15$ \\
\hline 6 & the factor of $P: 20$ \\
\hline 7 & the factor of $P: 10$ \\
\hline
\end{tabular}

Table 1: adjustments

Further let us remark that the main expressions are built so as to take particular values (2, 3 and 4 in this tablet; 5 and 10 in others).

How were the calculations done in practice? There is no trace of calculation techniques in cuneiform texts, probably because the operations were made on physical instruments. On this matter, the modern reader remains without resources. For instance, when performing an addition or a subtraction, the indetermination of the orders of magnitude poses a problem: the positioning of the numbers with respect to each other. Here, we shall limit ourselves to an empirical approach by noting that, if the numbers of our text are placed one under each other as they would be on an abacus, the data are usually lined up to the right. For example, the calculations that enable to verify the text of section 42 are the following:

\begin{tabular}{|l|l|r|r|l|}
\hline uš & & & 30 & \\
\hline sag & & & 20 & \\
\hline $2 \times($ uš - sag) & & & 20 & \\
\hline add & & 1 & 10 & \\
\hline $1 / 14$ & & & 5 & \\
\hline & & 2 & 29 & \\
\hline add & & 2 & 34 & \\
\hline $1 / 7$ & & & 22 & \\
\hline $1 / 11$ & & & 2 & \\
\hline add uš & & & 32 & \\
\hline
\end{tabular}

Table 2: 'abacus'

However this approach does not solve all the positioning problems of the text. For example, in section 26, the number 1 is not lined up to the right. Further, one might wonder where to place the number 10; the latter corresponds to the area whereas the numbers 30 and 20 correspond to the length and the width. I shall leave this last question aside for it does not specifically arise in this text ${ }^{21}$.

\footnotetext{
${ }^{21}$ It does arise however in other series, in which the statements give sums of lengths and areas, in particular in the twin tablet A 24195 and in one of the Louvre tablets. On this subject, see Proust 2009.
} 


\section{Structure and distribution of the information}

Let us return to the analysis of the text as a whole: How is the information organized and distributed among the different sections? The presentation of an excerpt has shown that the information contained in each statement can be decomposed into four segments:

- the area of a rectangle;

- a complex linear combination of the length and width of rectangle (P);

- a simple linear combination of uš and sag (S);

- a relation between the two expressions P and S.

The area of the rectangle is the same for all statements, whether explicit or not. The expression $\mathrm{P}$ takes several different values, each of which initiates a cycle of variants for expressions S; each new value of $S$ initiates a new cycle of variants for the relations between $\mathrm{P}$ and $\mathrm{S}$. Thus the text is built on a system of linked variants of the four components. The information is structured in the form of a four level tree: the highest (level 4) gives a first equation $\left(E_{1}\right)$; level 3 defines the main expressions $P$; level 2 defines the secondary expressions $\mathrm{S}$; finally level 1 , the lowest, defines the relations between $\mathrm{P}$ and $\mathrm{S}$, i.e. equations $\left(E_{2}\right)$. This structuring is shown in the diagram of appendix 2. Let us now specify the content of these different levels of information and the way the latter is distributed among the various sections.

\section{Level 4}

As we have seen, the tablet A 24194 is the tenth of a series. But the other tablets in the series are not known with certainty, therefore it is difficult to specify any differences between the tablets. The existence of tablet A 24195, very similar to tablet A 24194, allows us to suggest several hypotheses. The statements of tablet A 24194 form a homogenous group, each defining a system of two relations. The first (equation $\mathrm{E}_{1}$ ) is the same in all the statements of the text: 'the area is $1\left(\right.$ eš $\left._{3}\right) G A N_{2}$ '. The second (equation $E_{2}$ ) is a linear relation between uš and sag, which is subject to variations, following however a single model throughout the text. The statements of tablet A 24195 also form a homogenous group, but follow a different model than that of tablet A 24194. In A 24195, we have two quadratic relations between uš and sag. The variations concern both relations. For the rest, both tablets from Chicago are identical in every respect: same square format, same dimensions, same tiny writing, same way of structuring the information in a tree form, same reduction processes. Therefore, the two twin tablets A 24194 and A 24195 could represent two level 4 variants of the same series.

\section{Level 3}

Eight variants of expressions P occur in tablet A 24194. Given the state of the text, only three are identifiable: 
\#

\#42

$$
\mathrm{P}=\text { ? (text partly destroyed) }
$$

(4)

$$
\mathrm{P}=\left\{\frac{1}{14} \times[\text { uš }+ \text { sag }+2 \times(\text { us }- \text { sag })]+2.29\right\} \times \frac{1}{7} \times \frac{1}{11}
$$

\#54 $\mathrm{P}=$ ? (text partly destroyed)

\#81 $\mathrm{P}=$ ? (text partly destroyed)

\#119 $\mathrm{P}=$ ? (text partly destroyed)

$$
\begin{aligned}
& \# 139 \quad \mathrm{P}=\left\{\left[\left(\left(\frac{1}{2} \text { uš }\right)-\frac{1}{3} \times\left(\frac{1}{2} \text { uš }\right)+25\right] \times \frac{1}{7}+17\right\} \times \frac{1}{11}\right. \\
& \# 197 \quad \mathrm{P}=\left\{\left[\left((\text { uš }+(\text { uš }- \text { sag })) \times \frac{1}{4}+6\right) \times \frac{1}{8}+15\right] \times \frac{1}{11}+\text { uš }\right\} \frac{1}{8}
\end{aligned}
$$

\#242 $\mathrm{P}=$ ? (text partly destroyed)

Each new value of $\mathrm{P}$ initiates a cycle of variants of the other components of the statement. All the statements of the cycle use the same value $\mathrm{P}$ without mentioning it explicitly. For example, the value:

$$
\mathrm{P}=\left\{\frac{1}{14} \times[\text { uš }+ \text { sag }+2 \times(\text { us }- \text { sag })]+2.29\right\} \times \frac{1}{7} \times \frac{1}{11},
$$

defined in section 42, is used implicitly in all the sections that depend on it (\#43-53).

The values of $\mathrm{P}$ are defined in the long sections.

\section{Level 2}

To each of the variants of expression $\mathrm{P}$ corresponds a cycle of variants of expression S. In sections 1-41, $\mathrm{S}$ takes in turn the following values:

$$
\begin{aligned}
& S=u s ̌ \\
& S=\text { sag } \\
& S=u s ̌+s a g \\
& S=3 u s ̌+2 s a g \\
& S=u s ̌+(u s ̌-s a g) \\
& S=u s ̌ ~+s a g+2(u s ̌-s a g)
\end{aligned}
$$

This succession of values of $S$ is more or less found in all the cycles initiated by the variants of P, sometimes with a few omissions or with some new combinations. For example, in the cycle of sections 42-53, expression S has only two variants: uš and sag. But in other cycles, the variations are more developed: in addition to the six expressions given above, there are the expressions $S=1 / 3$ uš $+1 / 4$ sag (\#113), $S=1 / 3$ uš + 1/4 sag + (uš - sag) (\#180, \#231), $S=$ uš + 1/3 uš + sag + 1/4 sag (\#186).

Thus, the variations of $\mathrm{S}$ form relatively regular patterns. Note the significant fact that expression $\mathrm{S}$ is sometimes designated in the text as "uš/sag"22:

$$
\begin{array}{ll}
\# 25 & \text { 'uš/sag' designates the expression 3uš + 2sag } \\
\# 39 & \text { 'uš/sag' designates the expression uš }+ \text { sag + 2(uš - sag) } \\
\# 163 & \text { 'uš/sag' designates the expression 3uš + 2 sag } \\
\# 170 & \text { 'uš/sag' designates the expression uš + (uš - sag) }
\end{array}
$$

\footnotetext{
${ }^{22}$ In the cuneiform text, this concerns the juxtaposition of the signs uš and sag (this sequence by 'uš/sag' and not 'uš-sag' such as the usual transliteration norms would require; this, in order to avoid the graphical similarity with the subtraction uš - sag.
} 
\#177 'uš/sag' designates the expression uš + sag + 2(uš - sag)

\#221 'uš/sag' designates the expression uš + (uš - sag)

Each new value of $\mathrm{S}$ initiates a cycle of variants for the relations between $\mathrm{P}$ and $\mathrm{S}$. For each new value of $S$, all the following variants implicitly use this same value of $S$. For example, the value $S$ = uš defined in section 42 is implicitly used in all the following sections (\#43-48) until a new value of $S$ is defined (\#49).

The values of S are defined in the long and medium-sized sections. However, $\mathrm{S}$ is given explicitly in certain short statements, probably for grammatical reasons (see the above excerpt commentary).

\section{Level 1}

The relations between $\mathrm{P}$ and $\mathrm{S}$ also form quite regular patterns more or less composed of the following variants ( $\mathrm{N}$ designates a specified number):

$$
\begin{aligned}
& \mathrm{P}+\mathrm{S}=\mathrm{N} \\
& \mathrm{P} \times 2+\mathrm{S}=\mathrm{N} \\
& -\mathrm{P}+\mathrm{S}=\mathrm{N} \\
& -\mathrm{P} \times 2+\mathrm{S}=\mathrm{N} \\
& \mathrm{P} \times \mathrm{N}=\mathrm{S}+10 \\
& \mathrm{P} \times \mathrm{N}=\mathrm{S}-10
\end{aligned}
$$

The only element that changes from one cycle to another is the number $\mathrm{N}$; the writer of the text is able to produce a statement, whose solution is us $=30$ and sag $=20$, mainly by adjusting this number.

In each cycle of relations between $\mathrm{P}$ and $\mathrm{S}$, three types of relations alternate regularly:
A-ma B
$\mathrm{A}$ is $\mathrm{B}$ (translated A: B)
$\mathrm{A}=\mathrm{B}$
A B C diri
A exceeds $\mathrm{B}$ by $\mathrm{C}$
A B C ba-la 2
A is less than B by C
$\mathrm{A}=\mathrm{B}+\mathrm{C}$
$\mathrm{A}=\mathrm{B}-\mathrm{C}$

The relations between $\mathrm{P}$ and $\mathrm{S}$ (thus the equation $\mathrm{E}_{2}$ ) are defined at the end of the long and middle-size sections and in the short sections. It is at this level, i.e. at the leaf of the tree, that the main clause of each sentence is given: is (nominal clause), exceeds (diri), is less ( $\left(\mathrm{l}_{2}\right)$.

The structuring of the text is based on two combined processes: 1) a hierarchical organization of the information in four levels 2) a distribution of the information based on a system of elision: a piece of information common to several consecutive statements is given in the first statement and then is generally omitted in the following ones. The diagram in appendix 2 highlights these two processes: on the one hand the tree shows how the information is structured; on the other hand, the column to the right of the diagram gives the segments of information found in each section. Level 4 information corresponds to the definition of $\mathrm{E}_{2}$ (root of tree); level 3 information to the definitions of P (main nodes), level 2 information to the definitions of S (nodes); the level 1 information to equations E1 (leaves). The distribution of the information is the following: the long sections contain information of level 1, 2, 3 and 4; the middle-sized sections contain information of levels 1 and 2; the short sections contain level 1 information (and sometimes level 2 information for the grammatical reasons mentioned above). Let us insist on the fact that the structure of the information and its distribution are two independent aspects: for example, there are texts in which the information 
is given in the form of a tree structure, similar to that of A 24194, but with each section containing all the information ${ }^{23}$.

These writing techniques, plus the fact that the grammatical elements are mostly absent, lead to an extremely concise text. For instance, some sentences are so reduced that they are only formed of two signs (see for example section 16: 'zi 48').

The organization of the text is thus very rigorous. It is the reflection of a systematic search for concision and regularity. Is it pure virtuosity in the art of lists or does this structure have a significance of a different nature? In what follows, I shall show how tree structures increase the expressive possibilities of mathematical language.

\section{The writing of operations}

The expressions $\mathrm{P}$ and $\mathrm{S}$ are linear combinations of uš and sag. They are composed of arguments (numbers, uš, sag, linear combinations of uš and sag) on which operations act (additions, subtractions, repetitions, taking the Nth part). Does the expression of these operations follow regular rules? Is it identical on all levels of the tree? How do they relate to the structure of the text? Before answering these questions, let us further examine the different operations.

Addition is generally built with the verbal stem dah (to add), which is always placed after the $\operatorname{arguments}^{24}$ :
$\mathrm{A} \mathrm{B}-\check{s ̌ e}_{3}$ dah
A to B I have added
$\mathrm{A}+\mathrm{B}$

The suffix -še $e_{3}$ (terminative case suffix, translated in English by 'to') is often omitted. The arguments can be of all type (numbers or combinations of uš and sag), explicit or implicit. In the great majority of cases, the first argument is a main expression and the second is a secondary expression: For example:

\#49 $\quad$ sag-še ${ }_{3}$ dah

(P) to the width I added

$\mathrm{P}+\mathrm{sag}=22$

In this example, the first argument is implicit; it is an expression P defined previously \#42.

Addition can also be expressed by means of simple juxtaposition or coordination "and" $\left(\mathrm{u}_{3}\right)$, such as in section 42, line 20.

Subtraction is generally built with the verbal stem zi (to subtract), which is always placed after the arguments ${ }^{25}$ :
A B ba-zi
A from B I have subtracted
$-\mathrm{A}+\mathrm{B}$

Except for one case (\#139), both arguments are implicit. For example:

\footnotetext{
23 See for example YBC 4673, VAT 7528, YBC 4698, only to mention the tablets belonging to series (Neugebauer 1935-7).

${ }^{24}$ In the following, the ordinary arguments are denoted by the letters A, B etc. In the particular cases where they represent numbers, they are denoted $\mathrm{N}$, as mentioned above.

${ }^{25}$ Let us remark that the complete grammatical form would be A B-ta ba-zi, but the suffix -ta (ablative, translated by 'from') never appears in this text and the verbal prefix ba- is often omitted.
} 
There also is another way of expressing subtraction:
a-na A ugu B diri
That by which A exceeds B
$\mathrm{A}-\mathrm{B}$

It is a frozen formula in which the arguments are almost always uš and sag. For example:

\#42 a-na uš ugu sag diri That by which uš exceeds sag uš - sag

It is used in the secondary statements and in some of the main statements. In all cases, the arguments are explicitly given and placed immediately before the operator.

Repetition is the addition of an argument to itself a certain number of times:
A a-ra 2 N-e $\operatorname{tab}^{26}$
A repeated $\mathrm{N}$ times
$\mathrm{A} \times \mathrm{N}$

The argument $\mathrm{A}$ is often an implicit expression P. For example:
\#53 a-ra 2 10-e tab
(P) repeated 10 times
$\mathrm{P} \times 10$

Repetition is equally used in the main statements and in the secondary ones. The form is then often abbreviated and the operator can be placed before:
\#21 a-ra2 3 uš
3 times uš
$3 \times$ uš
\#42 a-ra 22 a-na ugu sag diri 2 times (uš - sag)
$2 \times($ uš - sag)

Let us note that the form "A a-ra $2 \mathrm{~N}$-e tab" is rarely found outside the mathematical series ${ }^{27}$. It constitutes a kind of neologism, which appeared well after the demise of Sumerian as a living language.

Operation of taking the $\mathrm{Nth}$ part (igi- $\mathrm{N}-\mathrm{gal}_{2}$, written $1 / \mathrm{N}$ in the formulae) appears in all the main expressions. The number of parts $\mathrm{N}$ is often a non regular sexagesimal number ${ }^{28}$ (for example 7, 11, 14). Generally, the operator is placed after the argument and carries a possessive suffix (-bi).
A igi-N-gal 2 -bi
A, its Nth part
$\mathrm{A} \times 1 / \mathrm{N}$

The argument $\mathrm{A}$ is then formed of everything preceding the operator igi-N-gal 2 within the section.

The operator igi-N-gal 2 is sometimes placed before the argument, as has been seen at the beginning of section 42. This construction is also found in certain secondary statements (\#113, 180, 231, 186):

$$
\begin{array}{lll}
\text { igi-3-gal } 2 \text { uš } & \text { The third of uš } & 1 / 3 \times \text { uš } \\
\text { igi-4 } \text { gal }_{2} \text { sag } & \text { The quarter of sag } & 1 / 4 \times \text { sag }
\end{array}
$$

In the cases where the operator igi-N-gal 2 is placed before the argument, the possessive suffix (-bi) disappears.

\footnotetext{
${ }^{26}$ About the construction N-e tab, see Proust 2009: 183-6.

${ }^{27}$ I have only found this exact form in tablet Str 366. It is found in slightly different forms in some tablets dating from the end of the Old Babylonian period (for example: A a-ra $2 \mathrm{~N}$ tab-ba in BM 85194), and in some tablets of the Schøyen Collection (for example: A $a$-na N-e tab in MS 2792, MS 3052, MS 5112 - see Friberg 2007). Let us note that according to J. Friberg, MS 5112 could date back to the Kassite period (16th- 12th century B.C.)

${ }^{28}$ This expression designates a number whose inverse cannot be written in base 60 with a finite number of digits. A number is regular in a given base if it can be written as the product of divisors of the base. In base 60, this means that its decomposition into prime factors only contains the factors 2, 3 and 5.
} 
The construction of igi-N-gal 2 is thus relatively regular: if the operator is placed after the argument, it carries the possessive suffix -bi and its argument is formed of everything preceding it in the statement; if it is placed before the argument, it does not take a possessive suffix and its argument is the term following it (generally uš or sag). However some ambiguities remain, mainly due to the frequent omission of grammatical suffixes. Section 42 , which begins with a fraction $1 / 14$ of everything following it, has a singularity that I cannot explain.

Let us now examine how the arguments and the operators are distributed in the sections. The constructions can be divided into two classes that will be called class I and II.

Class I: the arguments are explicit;

Class II: the arguments are implicit.

The constructions using the operators diri (to exceed), igi (Nth part of) and the additions by juxtaposition are mainly of class I. The constructions using the operators zi (to subtract) and tab (to repeat) are mainly of class II. This classification can be summarized in the following diagram (in which only the most frequent constructions for each operator are given). The constructions are placed in grids formed of three boxes: the first corresponds to the long sections, the second to the middle-sized sections and the third to the short sections. As previously, letters $\mathrm{A}, \mathrm{B}, \mathrm{C}$ refer to any argument, letters $\mathrm{P}$ and $\mathrm{S}$ denote the main and secondary arguments.

\section{Classe I constructions}

\section{dah (to add)}

\begin{tabular}{|l|l|l|}
\hline A B dah & & \\
\hline $\mathbf{u}_{3}$ (and) & & \\
\hline A B $\left(\mathrm{u}_{3}\right) \mathrm{C}$ & & \\
\hline or & A B $\left(\mathrm{u}_{3}\right) \mathrm{C}$ & \\
\hline
\end{tabular}

\section{diri (to exceed)}

\begin{tabular}{|l|l|l|}
\hline a-na A ugu B diri & & \\
or & a-na A ugu B diri & \\
\hline
\end{tabular}

\section{igi (to take an Nth part)}

\begin{tabular}{|l|l|l|}
\hline A igi-N-gal 2 -bi & & \\
\hline
\end{tabular}

or

\begin{tabular}{|l|l|l|}
\hline & igi-N-gal 2 A & \\
\hline
\end{tabular}

\section{Class II constructions}

\section{dah (to add)}

\begin{tabular}{|c|c|c|}
\hline $\mathrm{P}$ & $\mathrm{S}-\mathrm{Še}_{3}$ dah & \\
\hline or & & \\
\hline $\mathrm{P}$ & S-še $e_{3}$ & dah \\
\hline
\end{tabular}




\begin{tabular}{|l|l|l|}
\hline $\mathrm{P}$ & $\mathrm{S}$ & $\mathrm{zi}$ \\
\hline
\end{tabular}

tab (to repeat)

\begin{tabular}{|l|l|l|}
\hline $\mathrm{P}$ & & a-ra \\
\hline
\end{tabular}

This diagram shows several important phenomena with respect to class II constructions. As mentioned above, one has to go back up in the text in order to find the arguments on which the operators dah (to add), zi (to subtract) and tab (repeat) act. Further, this system of elision is only possible because the operator is placed after the arguments, thus placed at the end of the expression. Finally, due to the fact that the arguments are defined in previous sections, they form units enabling to express expressions with several levels of calculation. In some ways, these units play the same role as expressions inside brackets in modern algebraic notations. Let us note that the units $\mathrm{S}$ and $\mathrm{P}$ were recognized by the scribes as particular objects since a specific name was given to them. In this text, the unit $S$ is denoted in several cases by the expression 'uš/sag' (see above). In other texts belonging to mathematical series texts, the unit $\mathrm{P}$ is denoted by a kind of 'keyword', i.e. an 'igi-N-gal 2 ' expression that occurs in its definition (cf. Proust 2009). Therefore, the names 'P' and 'S' used in this article are not completely artificial in the sense that they refer to objects created and named by the scribes who practiced writing the series.

\section{Enumerative structure}

In connection with the questions raised in the other contributions of this book, one may wonder whether a text such as that of tablet A 24194 is an exotic specimen or whether it has its place within the system developed by J. Virbel to describe enumerations (p.xxx). Let us first remark that the text of tablet A 24194 presents in a particular acute manner one of the remarkable aspects of enumerations: the exploration of the utmost limits of the possibilities of writing. No oral discourse could completely reproduce the embedded system of elisions - on three or four levels - on which the text is built. The historians' difficulty today to see the link between this text and a spoken language (Sumerian or Akkadian) is probably a symptom of the fact that we are dealing with an elaboration based on writing, rather than speech.

But, is the list of statements of our tablet an enumeration? The colophon states that the tablet contains 240 sections ('im- šu'), and thus provides the nature and the number of components of the list, the items of which are formed of the sections and their content. Therefore the indications given in the colophon may be considered as some kind of an initializer to the enumerations; let us note however that the latter is placed at the end of the text and that the number 240 is not quite exact. The boxes delimited by horizontal and vertical lines represent the characteristic typographical features of enumerations (indents, bullets, etc.). The tree structure of the information corresponds to the model of embedded enumerations on different levels. And even though these different levels are not indicated by visual marks (such as the indentations used in the translated extract given at the beginning of this article), they are recognizable by the fact that each level contains items with a specific function in the sentence. The example of John's fruits (cf. p. xxx) might shed some light on this phenomenon. The 
enumeration structure of our tablet is of the same type as the one obtained by making a list of the possible variants of the sentence 'John likes apples':

$\begin{array}{ccl}\text { John } & \text { apples } & \text { likes } \\ & & \text { appreciates } \\ & \text { is able to eat } \\ \text { pears } & \text { likes } \\ & \text { appreciates } & \text { is able to eat } \\ & & \text { likes } \\ \text { oranges } & \text { appreciates } \\ & & \text { is able to eat } \\ \text { Lea } & \text { likes } \\ & & \text { appreciates } \\ & \text { is able to eat } \\ \text { pears } & \text { likes } \\ & \text { appreciates } \\ & \text { is able to eat } \\ \text { plums } & \text { likes } \\ & \text { appreciates } \\ & \text { is able to eat } \\ & \text { likes } \\ \text { oranges } & \text { appreciates } \\ & \text { is able to eat }\end{array}$

etc.

Level 1 information consists of verbs (likes, appreciates, is able to eat); it corresponds to the relations of our tablet. Level 2 information consists of fruits (apples, pears, prunes, oranges); it corresponds to the secondary expressions of our tablet. Level 3 information is only composed of people (John, Lea etc.); it corresponds to the main expressions of our tablet. It is therefore easy to distinguish the different levels. If the indentations were suppressed, it would nevertheless be possible to reconstitute the various items of this list:

John apples likes

appreciates

is able to eat

pears likes

appreciates

is able to eat

oranges likes

appreciates

is able to eat

Lea apples likes

appreciates

is able to eat

pears likes

appreciates

is able to eat

plums likes

appreciates 
is able to eat

oranges likes

appreciates

is able to eat

A comparison between the two enumeration presentations given here shows that the layout may constitute an aid for reading without providing any supplementary information. The lack of indentation makes the circulation within the text slower and more difficult, but does not introduce any reading ambiguities.

This illustration reveals other interesting aspects of our tablet. The system of elision is based on the fact that the verbs of the main clauses are placed at the end of the sentence or, in other words, on the fact that the corresponding operators are placed after the arguments. Moreover, it is easier to see how the partial initializer works at each enumeration level: the first item is at the same time the first item of the list and the initializer. The combinatorial nature of enumerations can also be seen: the system, ideally, could enable to consider all possible cases. And although the list of our tablet is not exhaustive, it aims at exhaustiveness.

\section{Circulation within the text}

As has been seen, an abridged statement in a short or middle-sized section represents a full statement which is formed of elements belonging to several related sections. How can these elements be identified? Let us first note that the main and the secondary expressions can be located by the size of the sections in which they are defined: the main expressions are found in the sections of approximately 6 lines, some of the secondary expressions are to be found in the 2 line sections, and some of the relations between $\mathrm{P}$ and $\mathrm{S}$ in the one line sections. Further, several textual or physical marks can be observed such as vocabulary, syntax, layout, lines between sections that help guiding the eye and, often, permit to grasp the content of a section at a glance.

Grammatical and lexical marks - As indicated above in the description of the enumerative structure, each level of information (main expression, secondary expression, relation) corresponds to a particular segment of the sentence (arguments, operator). These levels can thus easily be identified by both their vocabulary and syntax. The forms " igi-N-gal 2 " $(1 / \mathrm{N})$ where $\mathrm{N}$ is a non regular number, therefore remarkable, are only found in the main expressions (it is the case of the suffix - še $e_{3}$ ). Similarly, the form "a-ra 2 N-e tab" (N times I repeated) is only found in the relations between $\mathrm{P}$ and $\mathrm{S}$; it is the same for the suffix -ma. These specific terms and constructions thus enable to distinguish the levels of information in the sections.

Change of column - Does the layout of the text in the different columns take into account the information levels of the tree? At first glance, it seems not, as can be seen in the following table 3 .

\begin{tabular}{|l|l|l|}
\hline End of column & Movement in the tree & Information of the text: \\
\hline obv. I & $1->3$ & goes up two levels \\
\hline obv. II & $3->3$ & stays on level 3 \\
\hline obv. III & $1->3$ & goes up two levels \\
\hline
\end{tabular}




\begin{tabular}{|l|l|l|}
\hline obv. IV & $1->2$ & goes up one level \\
\hline obv. V & $1->1$ & stays on level 1 \\
\hline rev. I & $1->1$ & stays on level 1 \\
\hline rev. II & $1->1$ & stays on level 1 \\
\hline rev. III & $1->1$ & stays on level 1 \\
\hline rev. IV & $1->1$ & stays on level 1 \\
\hline rev. V & $1->?$ & goes to the following tablet \\
\hline
\end{tabular}

Table 3: Layout of the text on the tablet

For example, at the end of the second column of the obverse there is a change of column in the middle of a statement. The scribe prefers to write the first line of a new section at the end of a column, where there remains little room, rather than moving to the next column for the section to be all in one block. In this case, the change of column could have been used to indicate a change of level. The chosen layout shows that the main constraint is the density of the writing: the text is packed as much as possible into the available space. However there are three places where the text moves up a level in the case of a change in column (end of columns obv. I, III, IV). A fourth location is at the end of the last column, which corresponds to a tablet change: the tablet is complete, as indicated by the presence of the colophon, and the following tablet probably starts with a long section ${ }^{29}$.

In conclusion, the layout of the text does not entirely follow the distribution of the information: the changes of column do not always correspond with the changes of level. This dissociation between the physical and textual elements is sometimes also observed on a different scale: the tablets of the series ${ }^{30}$.

Section lines - The statements are placed in sections delineated by simple or double lines. Are these double lines related to the structure of the text? It is difficult to analyze this kind of detail on the sole basis of the copy of the text. However, an examination of the original shows that, in his copy, Neugebauer carefully kept the distinction between simple and double lines, even though the condition of the tablet does not always allow such a clear distinction. The positions of the double lines that are clearly identifiable are the following

\begin{tabular}{|l|l|l|l|}
\hline \multicolumn{1}{|c|}{ Between short sections } & $\begin{array}{l}\text { Between short and } \\
\text { middle-sized } \\
\text { sections }\end{array}$ & $\begin{array}{c}\text { Between short } \\
\text { and long } \\
\text { sections }\end{array}$ & $\begin{array}{l}\text { Between short } \\
\text { sections and ? }\end{array}$ \\
\hline $\begin{array}{l}15,43,77,78,139,143,144,146, \\
147,152,153,160,173,174,175,23,145,151,\end{array}$ & $\begin{array}{l}48,80,118,138 \\
187,223\end{array}$ & $\begin{array}{l}247 \text { (end of the } \\
\text { tablet) }\end{array}$ \\
\hline
\end{tabular}

\section{Table 4: double lines in A 24194}

According to this table, there seems to be no strict rules. However, we can see that out of the six visible long sections, four begin with a double line. It is therefore possible that the distribution of the double lines might have helped to locate pieces of information.

Although these various marks are useful, they do not permit comfortable circulation within the text; other signs might have existed that cannot be seen today. In any case it is likely that

\footnotetext{
${ }^{29}$ It is rare for a statement (or a cycle of statements) to begin on one tablet and end on another. Nevertheless, this case is documented (see tablet AO 9072, Proust 2009).

${ }^{30}$ For example, the thematic groupings of statements may not correspond to the groupings by tablets (Ibid).
} 
to skim through such a text required much expertise. This poses the problem of the reading mode and use of such types of texts.

\section{Conclusion}

Let us go back to the questions concerning the function of the text that were raised in the introduction. Does tablet A 24194 contain a collection of problems for teaching, as Neugebauer thought? This question raises two others, larger in scope: what was teaching at the time the text was written? What were the relations between the scribes that produced the scholarly texts and those who gave the instruction? It is beyond the scope of this article to tackle these questions in detail. Let us just underline some important data in this regard. Old Babylonian elementary instruction is well documented thanks to the thousands of pupils' rough copies found near the teaching locations. Further, the Old Babylonian scholarly mathematical texts of known origin (Ur, Nippur, Tell Harmal, Susa...) have almost always been found associated with school remains. This suggests that the authors of the erudite mathematical texts had close connections with the scribal school milieus, or at least with teaching activities. Unfortunately, as stated in the introduction, the discovery context of tablet A 24194 is not known, neither is that of the other mathematical series, therefore no archeological evidence informs us about their possible date ${ }^{31}$, origin or the relation between these series and the scribal schools. Further, to my knowledge, most of the statements of our tablet have no parallel in the mathematical cuneiform documentation available today, in particular in that of the Old Babylonian period. Indeed, tablets containing solved problems, of which statements are similar to the ones found at the beginning of some series. But none of them reach the level of complexity found in the Chicago tablets or in many mathematical series texts ${ }^{32}$.

Of course, these arguments ex silentio are not evidence and the only fact is that there are no sources - neither archeological nor textual - that might shed some light on a possible teaching context. Yet, let us add another argument. Some mathematical series have statements leading to equations of the third or fifth degree that the scribes obviously were unable to solve. In this case, Neugebauer's interpretation, cited at the beginning of this article (It is obvious that a collection of this sort was used in teaching mathematical methods), has to be ruled out. Although we remain cautious concerning the Chicago tablets, it is nevertheless possible to state that the series are not all 'reservoirs of problems for teaching'. Further, the characteristics of the text and its probable late date might indicate that it belongs to the emerging tradition of scholarly compilations i.e. a possibly different intellectual milieu than that of the Old Babylonian schools.

Let us try to clarify some of the intentions reflected by the content of the text itself. The structure of the text shows how the statements are constructed, in a systematic way, by the

\footnotetext{
${ }^{31}$ As mentioned above, it is generally believed that the series date back to the end of the Old Babylonian period (17 ${ }^{\text {th }}$ century B.C.).

${ }^{32}$ See in this regard the comparative study of a list of solved problems (BM 13901) and a list of statements from a series text (YBC 4714), in which J. Høyrup shows a connection between the problems in terms of the topics (concentric squares) and the resolution methods considered, so far as one can reconstruct them as regards the tablet YBC 4714. He notes however that the variants found in the series are much more sophisticated than those found in the list of solved problems. He suggests that one of the first tablets of the series to which YBC 4714 belongs might contain statements similar to those of tablet BM 13901 (Høyrup 2001, p.199).
} 
interplay of linked variants acting on the different segments of an initial statement. The selection criteria and the classification of the problems are due to this process of statement construction, and thus are not based on the resolution methods which are not addressed in the text. This distinguishes our text - and series in general - from a list of problems such as that of tablet BM 13901 mentioned above, the organization of which is mainly based on the resolution methods. In tablet A 24194, the scribe's efforts concentrate on the elaboration of the statements, both with respect to their form (writing style) and substance (mathematical content).

The list of statements is generated by specific writing techniques: tree structure of the information, combinatory method of exploration of the possible, rationalized distribution of the information by means of elision, logographic writing, reduced and specialized vocabulary including neologisms. In particular, these techniques allow dealing with difficulties created by the need to determine the hierarchy of operations that are dealt with today by using parentheses. Therefore the resources of ordinary writing are increased; these techniques permit writing highly complex operations. The result is an extremely concise style. Thus, this conciseness seems more a consequence of the writing constraints of the statements than an objective in itself. Nevertheless brevity is clearly valued. Indeed, we have seen that the tablet filling strategies favored the compactness of the text rather than its readability, and that the omission of grammatical particles was a general phenomenon, even though it could lead to ambiguities. Let us remark that the search for conciseness is much greater in the two Chicago tablets than in the other mathematical series. Therefore, the writing techniques are directly related to the purpose of the text, which is the production of statements, but they also seem to have been developed for their own sake.

If the mathematical content does not concern the methods of problem resolution, than what is it? The statements obey two strong mathematical constraints. The first is that the statements contain the necessary and sufficient information for their resolution, i.e. two independent relations between two unknowns. The second is that the problems can be reduced to quadratic equations and are therefore solvable, at least theoretically, by means of mathematical procedures known at the end of the Old Babylonian period. We might wonder whether the scribes were aware of the fact that their method of statement generation - which essentially consisted in modifying a linear relation between unknowns starting from a standard initial problem - always led to problems they could solve, even if the resolution in question was not effective. More precisely, we can hypothesize that the purpose of the text is precisely the relation between modes of producing problem statements and the possibility of solving them in theory. 


\section{Appendix 1: Copy of tablet A 24194}

(Neugebauer and Sachs 1945, pl. 15)

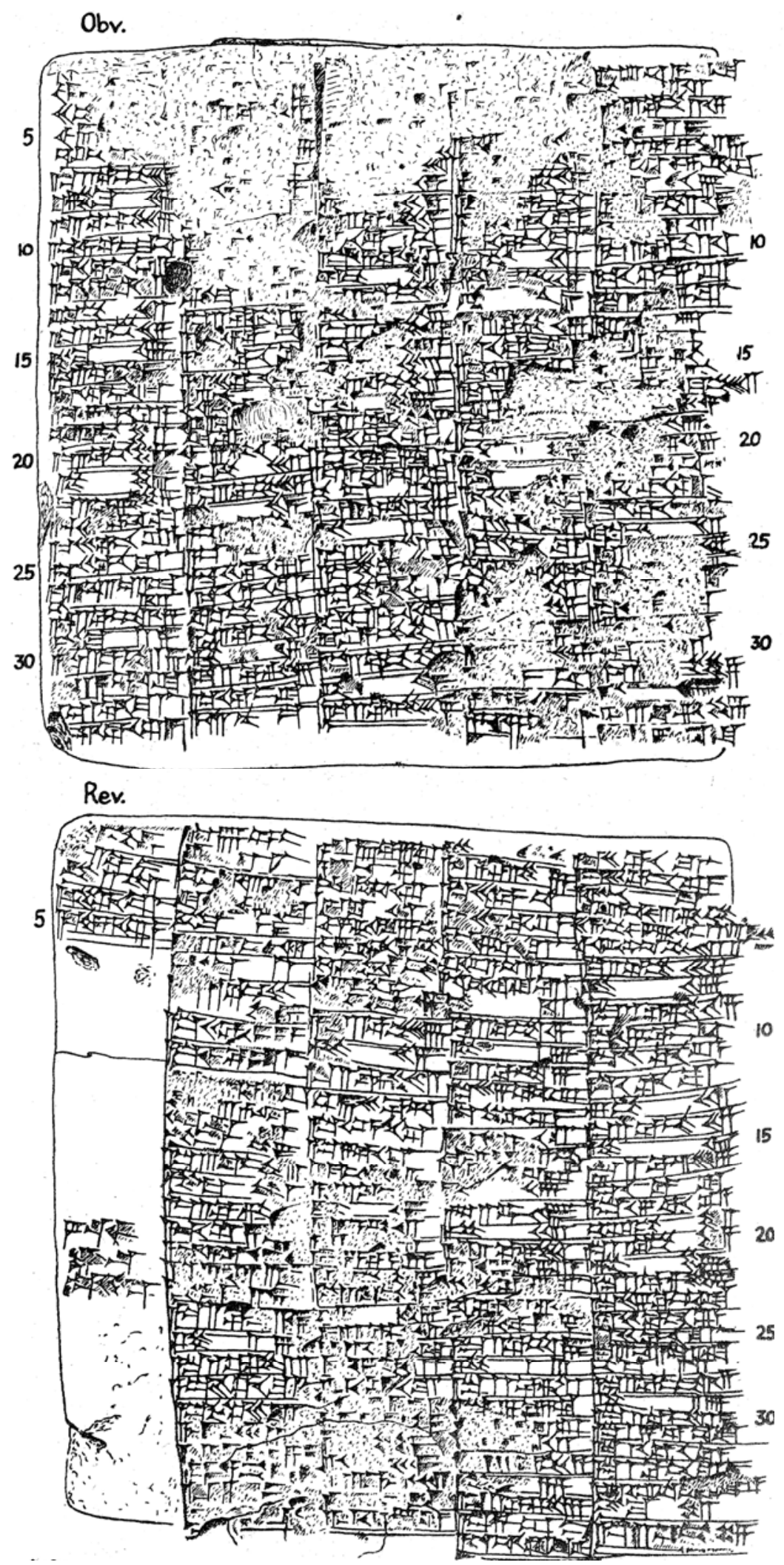




\section{Appendix 2: Structure and distribution of the information}

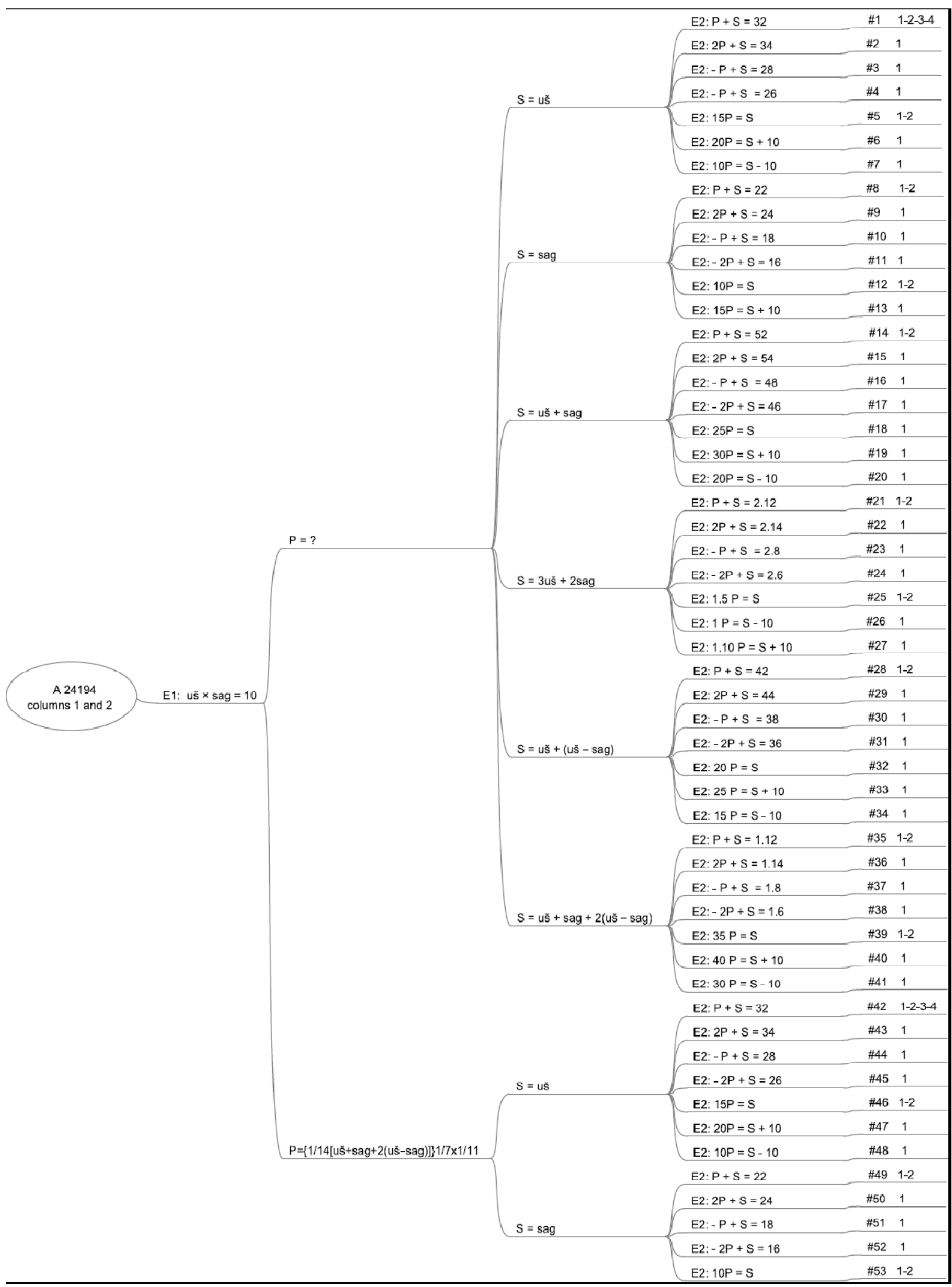

\section{Legend}


The branches of the tree correspond to the different levels of information: root = level 4; main nodes $=$ level 3; secondary nodes =level 2; extremities=level 1 . The column located to the right gives the number and content of the sections that correspond to each path in the tree.

\section{Appendix 3: Glossary}

This glossary is a list of forms attested in the extract analyzed in this article. The notations are the same as before: $\mathrm{N}$ denotes specified numbers and the letters $\mathrm{A}, \mathrm{B}$ and $\mathrm{C}$ denote any type of expression (specified numbers, uš, sag, simple or complex combinations of uš and sag, explicit or implicit). The grammatical suffixes and prefixes frequently omitted in the cuneiform text are given in parentheses.

\section{Arguments}

uš

sag

a-ša 3

\section{Relations}

A-ma B

A-ma ugu B C diri

A-ma B C ba-la 2

\section{Operations}

A B-( $\left(\mathrm{se}_{3}\right)\left(\mathrm{bi}_{2}\right)$-dah

A B GAR.GAR

$\mathrm{A} \mathrm{u}_{3} \mathrm{~B}$

A B

A B (ba)-zi a-na A ugu B diri

$\mathrm{A}$ a-ra 2 N-e tab

A igi-N-gal-(bi)

igi-N-gal 2 A length

width

area

\section{A: B}

A: exceeds $\mathrm{B}$ by $\mathrm{C}$

$A$ : is less than $B$ by $C$

$$
\begin{aligned}
& A=B \\
& A=B+C \\
& A=B-C
\end{aligned}
$$

A to B I added

A B I accumulated

$\mathrm{A}$ and $\mathrm{B}$

$\mathrm{A}+\mathrm{B}$

"

"

"

$-\mathrm{A}+\mathrm{B}$

A, from B I subtracted

$\mathrm{A}-\mathrm{B}$

That by which A exceeds $B$

$\mathrm{A} \times \mathrm{N}$

$\mathrm{A} \frac{1}{\mathrm{~N}}$

A, its Nth part

$\frac{1}{\mathrm{~N}} \mathrm{~A}$ 


\section{Bibliography}

Friberg, Jöran (2007) A Remarkable Collection of Babylonian Mathematical Texts. Manuscripts in the Schøyen Collection: Cuneiform Texts Vol. I. New York: Springer.

Glassner, Jean-Jacques (2009) 'Ecrire des livres à l'époque paléo-babylonienne: le traité d'extispicine', Zeitschcrift für Assyriologie und Vorderasiatische Archäologie 99: 1-81.

Høyrup, Jens (2006) 'Artificial Language in Ancient Mesopotamia - a dubious and less dubious case', Journal of Indian Philosophy 34: 57-88.

Neugebauer, Otto (1935) Mathematische Keilschrifttexte I. Berlin: Springer.

(1935-7) Mathematische Keilschrifttexte II-III. Berlin: Springer.

Neugebauer, Otto \& Abraham J. Sachs (1945) Mathematical Cuneiform Texts. American Oriental Studies Vol. 29. New Haven: AOS \& ASOR.

Proust, Christine (2008) 'Quantifier et calculer: usages des nombres à Nippur', Revue d'histoire des mathematiques 14: 143-209.

(2009) 'Deux nouvelles tablettes mathématiques du Louvre: AO 9071 et AO 9072', Zeitschrift für Assyriologie 99: 1-67.

(2012) 'Reading colophons from Mesopotamian clay-tablets dealing with mathematics.' NTM Zeitschrift für Geschichte der Wissenschaften, Technik und Medizin Vol. 20: $123-56$. 